\title{
The Effect of Borax Solution as Preservative to the Mechanical Properties of Bamboo
}

\author{
M.A.P Handana ${ }^{1 *}$, Besman Surbakti ${ }^{1}$, Rahmi Karolina ${ }^{1}$ \\ ${ }^{1}$ Department of Civil Engineering, Universitas Sumatera Utara \\ Dr. T. Mansyur 9, Medan, 20222, INDONESIA \\ *Corresponding Author
}

DOI: https://doi.org/10.30880/ijscet.2020.11.02.009

Received 30 July 2020; Accepted 30 August 2020; Available online 02 September 2020

\begin{abstract}
The use of borax solution as a preservative in wood and bamboo materials is well known in the community. A borax solution is an environmentally friendly liquid that can dissolve in water, so it is suitable to be used as a preservative within cold or hot soaking techniques. The ability of borax to resist insects and fungus attacks on bamboo has been proven, but the effect of the solution on the strength of bamboo must also be investigated. This study conducts to investigate the effects of borax and its additives as preservative solutions to the mechanical properties of bamboos. The bamboos preservations were conducted by cold conditions of immersion, while the mechanical properties were performed to understand the effects of preservatives. The result of this study indicated that $30 \%$ to $50 \%$ borax in the preservative solution is sufficient to provide significant increase in strength for compressive strength, tensile strength, and bending strength of bamboo specimen. From this study, the use of borax solution in preserving the bamboos materials improved the quality of bamboos based on its mechanical properties.
\end{abstract}

Keywords: Bamboo; Borax preservative; Bending Strength; Compressive strength; Shear strength; Tensile strength

\section{Introduction}

Indonesia as a tropical country has been utilizing wood and bamboo as a wood-like material as a building component. The experience of using bamboo provides a lesson that bamboo is very vulnerable to natural disturbance, reducing the lifespan of the building. Due to its biodegradable properties, degradation in bamboos can be caused by either biotic or abiotic origin, which suggests their low natural durability (Walter Liese \& Kumar, 2003). Biotic organisms which attack a bamboo are commonly insects and fungi, which consume this material as food in form of culm for their growth and survival (Bhawan \& Marg, 2007).

The endurance of a bamboo species to be attacked certain destructive organisms such as termites, powder-post beetles, marine borers and a decay fungus is related to its natural durability. Bamboo resistance indicates the durability of a bamboo species against destroying organism and this could be affected by some factors influencing bamboo resistance such as site, growth rate, age, portion of bamboo, extractives content and the microenvironments (Suprapti, 2010; Schmidt, Wei \& Tang TKH, 2013). Constructional methods are often applied to avoid the damages caused by destructive organisms.

One of the methods in keeping the bamboo components is by drying the material below the fiber saturation point, so that no fungal attack can occur. A centuries-old tradition for the proper construction use of bamboo without chemical 
treatment exists; commonly by placing bamboo or walls on either stones, pre-formed concrete footings or durable/pressure treated wood blocks, instead of putting them directly onto the ground. The culm should be cut just below a node for better stability instead of placing it directly into the concrete as it may shrink, leading to an interspace for moisture and humidity to be facilitating fungal attacks (Larasati, 2007).

Other than traditional method to preserve bamboo, protection with chemical preservatives is often used. The characteristics of an ideal preservative as it has been reported are: (i) toxicity to the target organism and minimum toxicity to the non-target organism, (ii) permanent fixation inside the bamboo culm, (iii) high penetration inside the bamboo tissues, (iv) easy disposal of treated product, and (v) strength of treated culm not affected by preservative impregnation (Walter Liese \& Kumar, 2003). Environmental-friendly and water-borne preservatives have the ideal characteristics because these can penetrate the tissue of moist culms by diffusion process for achieving the protection.

In preserving the wood materials, boron compounds are the most common methods that have been utilized. It also has been reported that the use of Chromated Copper Arsenate (CCA) and Chrome Cooper Boron (CCB) types are used in Asia and other bamboo regions, preferably by factories which normally treat timber (Liese, 2007). Boron preservative compounds have no adverse impact on environment as long as it has been used in appropriate dosages. The properties of boron are odourless, colourless, no reactivity to metal, non-volatile and the prices relatively cheaper than heavy metal-based preservatives. Given that Boron elements are contained within the borax, this material could be utilized as alternatives in preserving the bamboo materials. The details of borax properties are given in Table 1 (Ninez, Prinindya, \& Ardiansyah, 2014).

Table 1 - Borax Properties

\begin{tabular}{cc}
\hline Molecular Formula & $\mathrm{Na}_{2} \mathrm{~B}_{4} \mathrm{O}_{7} .10 \mathrm{H}_{2} \mathrm{O}$ \\
\hline Physical State & White or colourless crystalline powder \\
\hline Odour & $741^{\circ} \mathrm{C}\left(1365.8^{\circ} \mathrm{F}\right)$ \\
\hline Melting Point & 1.71 \\
\hline Specific Gravity & $11.34 \%$ \\
\hline \% Boron & 381.37 \\
\hline Molecular Weight & $4.71 \%$ \\
\hline Solubility in Water
\end{tabular}

Borax solutions are effective to protect bamboo from destructive organisms (Tang, Schmidt, \& Liese, 2009). Therefore, varied of concentrations of borax solutions can affect the mechanical properties of bamboos such as $10 \%$, $20 \%, 30 \%, 40 \%, 50 \%$, and $60 \%$ are conducted to investigate in this research to the effects of the mechanical properties of bamboo. This research also aims to investigate the effects of nodal at the test specimen to mechanical properties of bamboo.

\section{Material, Specimen, and Testing}

\subsection{Preparation}

The bamboo species that involved in this research is Dendrocalamus Asper taken from Deli Serdang Regency in eastern region of Sumatera Utara Province. This species of bamboo is widely known in this area because it can be found in commonly in this region (Saputri, 2012). The bamboo culms of $200 \mathrm{~cm}$ length were left to be dried for two weeks (Fig. 1). Non-pressure treatment by immersing the bamboo culms in cold conditions were chosen as the preservative method. The bamboo culms were treated by keeping them submerged in water-borne preservative solution. The preservative were adsorbed into the bamboo due to the gradient concentrations, and the cell sap moved out due to osmotic pressure (Bhawan \& Marg, 2007). Every variation of borax solution was prepared in cylinder tanks for the soaking methods, while the bamboo culms were immersed inside the cylinder tank for 14 days (Fig. 2). After each cycle of treatments, the solution inside the tank was changed to ensure the same processing method to every bamboo culms. 


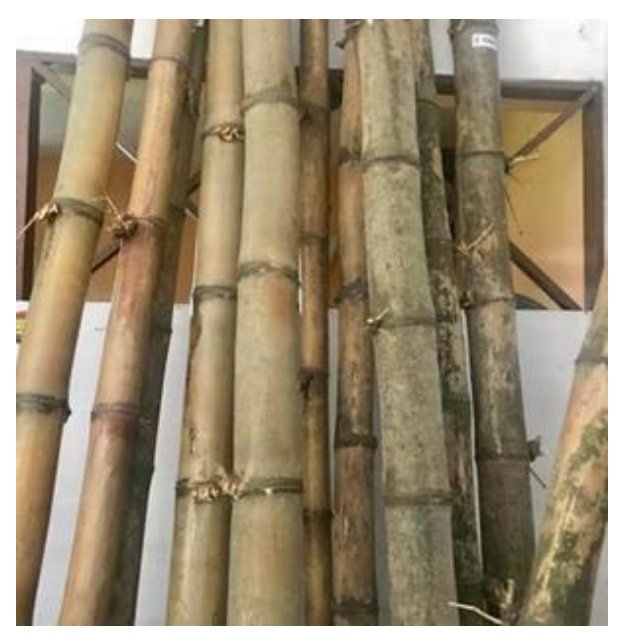

Fig. 1 - Preparation work for bamboo culm

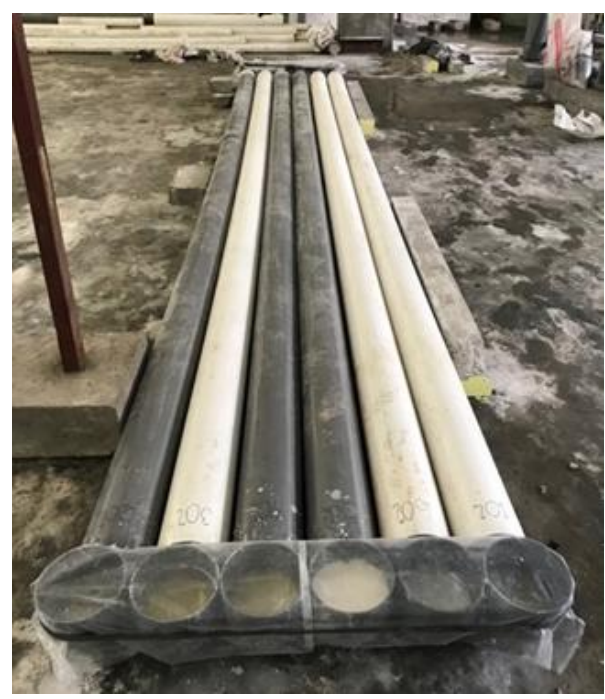

Fig. 2 - Bamboo soaking process

After the bamboo culms being removed from the cylinder tank and stacked vertically for another 14 days, these culms were cut into small specimens for compression, shear, tensile, and bending test. Five random specimens in internode and node region from the bamboo culms were selected for each type of test, which can be seen from Table 2 .

Table 2 - Sample Distribution

\begin{tabular}{|c|c|c|c|c|}
\hline \multirow{2}{*}{ Percent of Borax } & \multicolumn{4}{|c|}{ Number of Specimens } \\
\hline & Compression & Shear & Tensile & Bending \\
\hline \multirow{2}{*}{$0 \%$} & 5 nodes & 5 nodes & 5 nodes & 5 nodes \\
\hline & 5 internodes & 5 internodes & 5 internodes & 5 internodes \\
\hline \multirow{2}{*}{$10 \%$} & 5 nodes & 5 nodes & 5 nodes & 5 nodes \\
\hline & 5 internodes & 5 internodes & 5 internodes & 5 internodes \\
\hline \multirow[b]{2}{*}{$20 \%$} & 5 nodes & 5 nodes & 5 nodes & 5 nodes \\
\hline & 5 internodes & 5 internodes & 5 internodes & 5 internodes \\
\hline \multirow{2}{*}{$30 \%$} & 5 nodes & 5 nodes & 5 nodes & 5 nodes \\
\hline & 5 internodes & 5 internodes & 5 internodes & 5 internodes \\
\hline \multirow{2}{*}{$40 \%$} & 5 nodes & 5 nodes & 5 nodes & 5 nodes \\
\hline & 5 internodes & 5 internodes & 5 internodes & 5 internodes \\
\hline \multirow{2}{*}{$50 \%$} & 5 nodes & 5 nodes & 5 nodes & 5 nodes \\
\hline & 5 internodes & 5 internodes & 5 internodes & 5 internodes \\
\hline \multirow{2}{*}{$60 \%$} & 5 nodes & 5 nodes & 5 nodes & 5 nodes \\
\hline & 5 internodes & 5 internodes & 5 internodes & 5 internodes \\
\hline
\end{tabular}




\subsection{Compression Test}

Compression tests paralleled to the axis were made on the specimens with node at the centre and without node (internode). The length of the specimen was prepared to be twice of the outer diameter (Fig. 3).
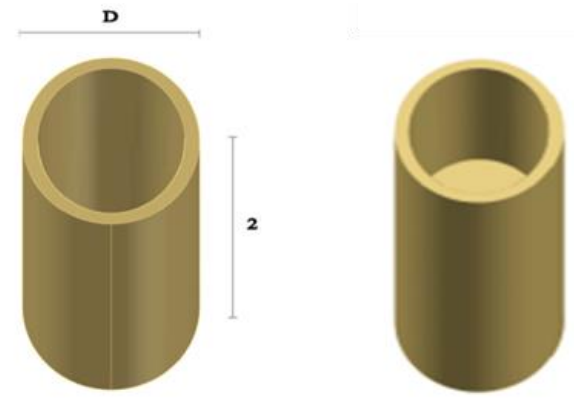

Fig. 3 - Compression Test specimen

Five center node specimens and five node specimens were tested, followed by placing and testing on Compression Testing Machine (Fig. 4) under a constant rate of $0,01 \mathrm{~mm} / \mathrm{s}$ until the specimen failed as described in ISO 22157 1:2004 (22157-1, 2004). The compression strength was determined based on average value of maximum load recorded for each specimen. The following Fig. 4 displays the compression tests performed.

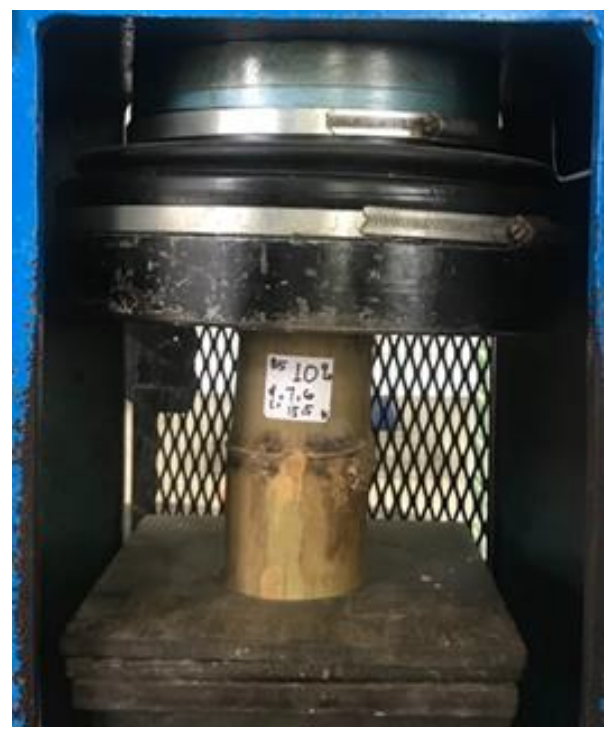

Fig. 4 - Set up for Compression Test

\subsection{Shear Test}

Shear test paralleled to the axis were performed with the specimens as it is shown in Fig. 5. The specimen taken from bamboo strips were tested with 5 specimens with node at the centre node and another 5 specimens without node (internode). The maximum loads for each specimen were recorded, and the shear strength was calculated from the average value of all recorded results. The specimens were tested based on the Universal Testing Machine (Fig. 6).
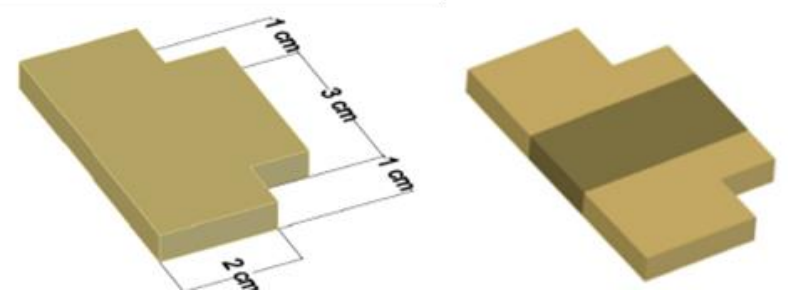

Fig. 5 - Shear Test specimen 


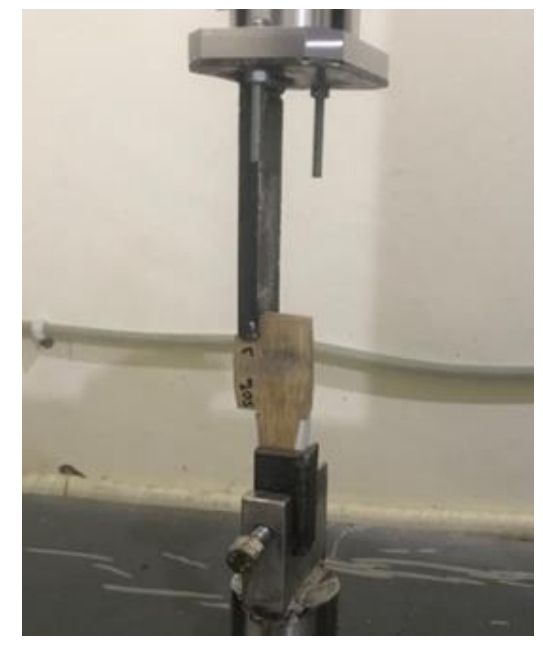

Fig. 6 - Set up for Shear Test

\subsection{Tensile Test}

Tensile test specimen as described in ISO 22157-2:2004 had a unique shape (22157-2, 2004) (Fig. 7). All of the specimen were cut parallel to the grain and prepared with node at the centre node and without node (internode). The specimen tested under a constant rate of $0.01 \mathrm{~mm} / \mathrm{s}$ on an Universal Testing Machine (Fig. 8).

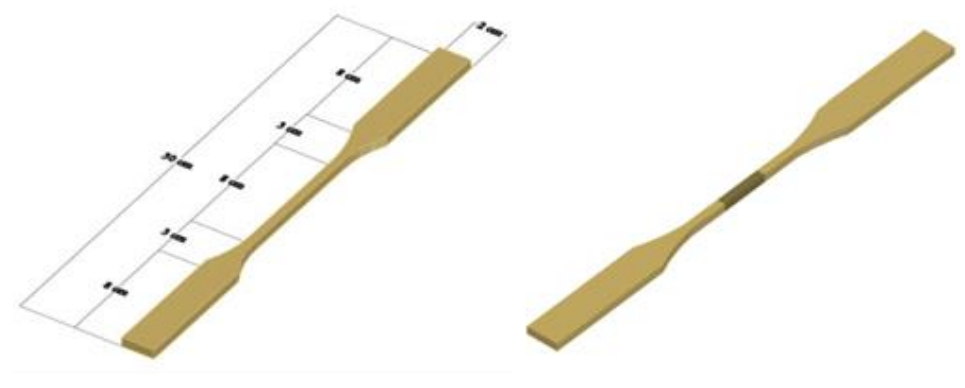

Fig. 7 - Tensile Test specimen

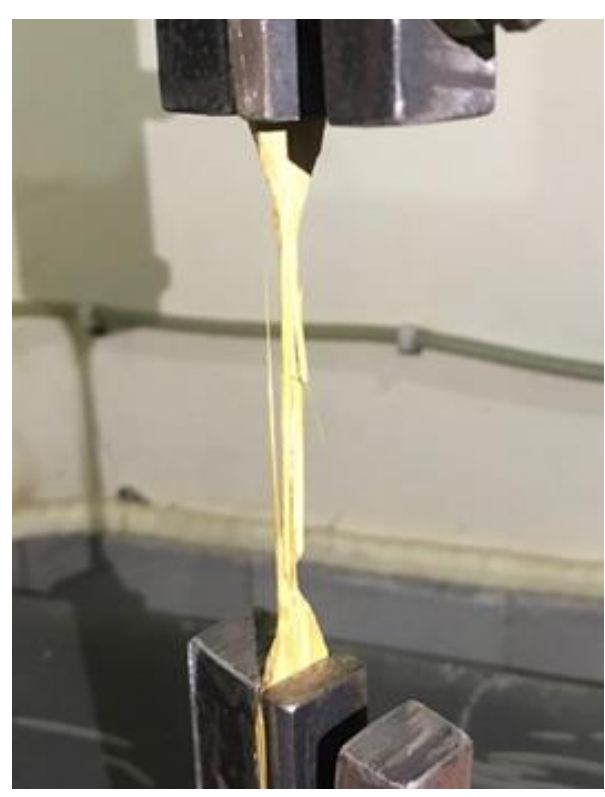

Fig. 8- Set up for Tensile Test 


\subsection{Bending Test}

Bending test was conducted on $\mathrm{t}$ x $15 \mathrm{~mm}$ x $200 \mathrm{~mm}$ bamboo strip (Fig. 9), where $\mathrm{t}$ was the thickness of bamboo strip. The bamboo strip specimens were centre node and without node (internode). The bending test method was three points loading, and the test was conducted on Universal Testing Machine (Fig. 10), while the maximum bending load was recorded to the specimens. The average values from test result were calculated to determine the bending strength.
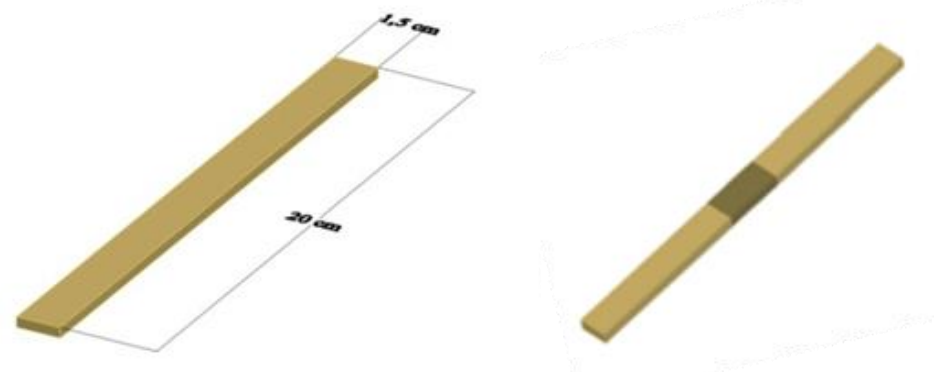

Fig. 9 - Bending Test specimen

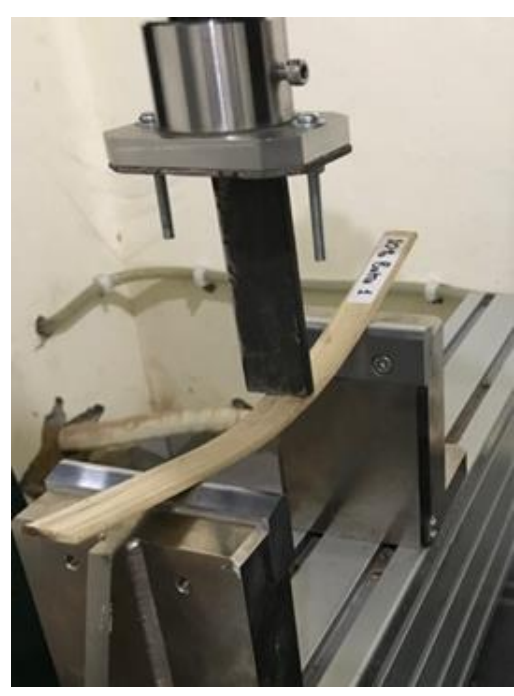

Fig. 10 - Set up for Bending Test

\section{Results and Discussions}

\subsection{Compressive Strength}

Different failure patterns of bamboo specimen after compressive test are shown in Fig. 11 below. Internode bamboo specimen had vertical crack pattern while the center node of the bamboo specimens had bearing failure pattern.

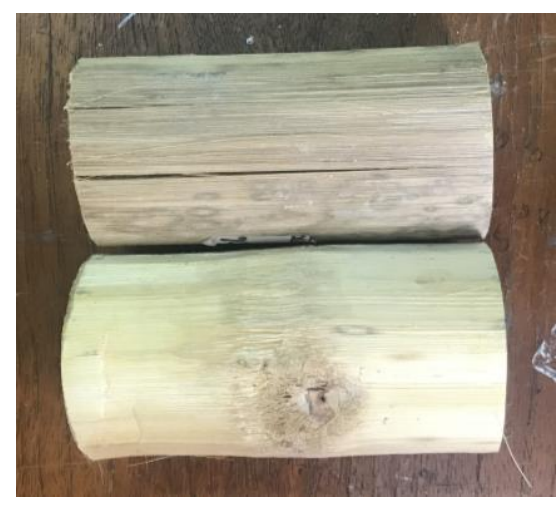

Fig. 11 - Failure pattern of compressive test specimen 
Compressive strengths of center node and internode bamboo specimens are reported in (Fig. 12).

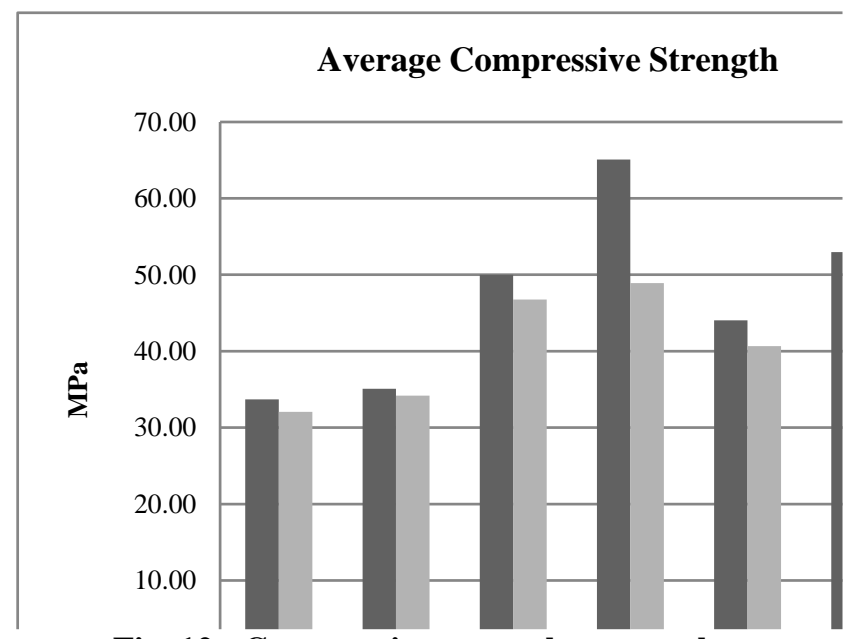

Fig. 12 - Compressive strength test results

From the result, the average compressive strengths from centre node of bamboo specimens were slightly weaker than those from the internode bamboo spesimens. This result is similar to a previous research that studied the effect of node and internode on the mechanical properties of bamboos (Oka, Triwiyono, Awaludin, \& Siswosukarto, 2014). The previous research shows the average compressive strength from node specimen was $50.50 \mathrm{MPa}$, while the average compressive strength from internode specimen was 52.27 MPa. The result from the previous research also shows that the use Borax solution as preservative also provided small effects to the compressive strength of the spesimen in particular for the centre node site. $30 \%$ percentage of borax provided the highest compressive strength for both the centre node and internode bamboo specimens.

\subsection{Tensile Strength} 13).

Failure pattern of centre node and internode bamboo from tensile test occurs in reduced area of the specimen (Fig.

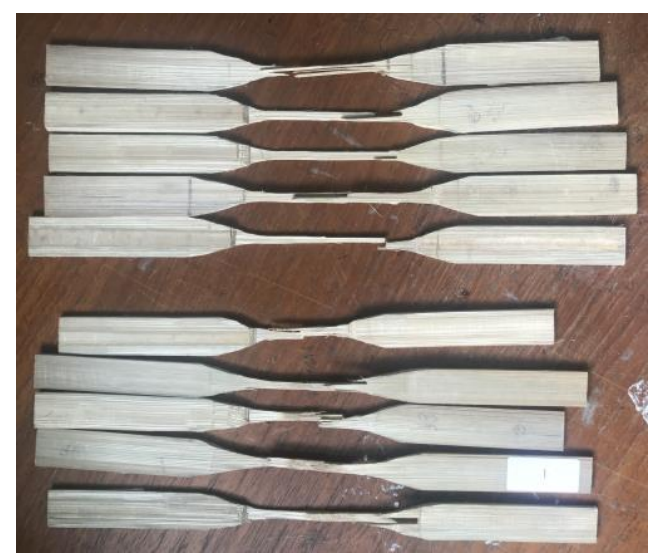

Fig. 13 - Failure pattern of compressive test specimen

The following Fig. 14 displays the tensile test results of the center node and internode of bamboo specimens. These results are satisfactory because a previous research shows that the average tensile strength of Dendrocalamus Asper bamboo that grew and preserved with borax solution in neighbouring country, Perak, Malaysia was $221.95 \mathrm{MPa}$ (Awalluddin et al., 2017). The result also shows that node can greatly be reduced the tensile strength of bamboo specimens. As for the effect of borax solution as preservative, 50\% percentage of borax solution provided the highest tensile strength. The increase of strength affected to the centre node and internode bamboo specimens. 


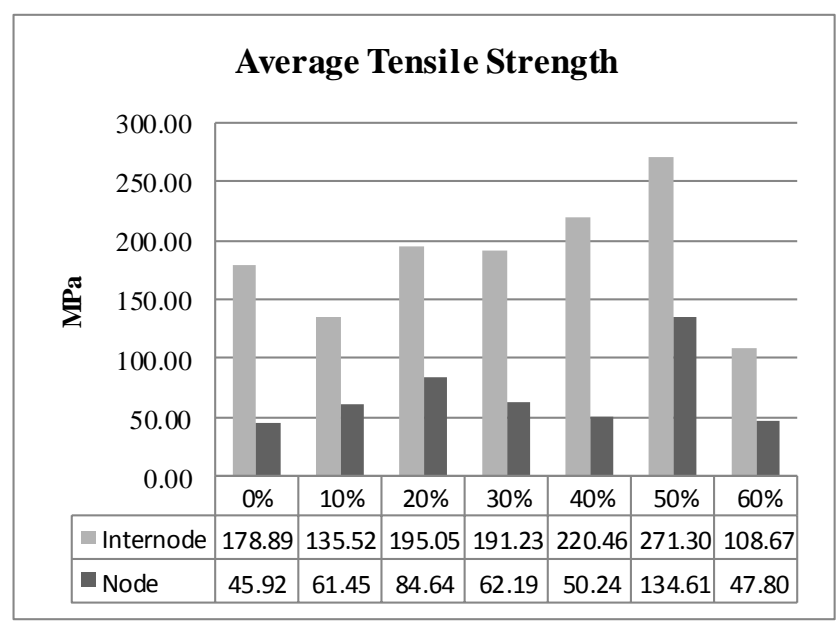

Fig. 14 - Tensile strength test results

\subsection{Shear Strength}

Centre node and internode bamboo specimen shows same failure pattern after shear test was conducted.

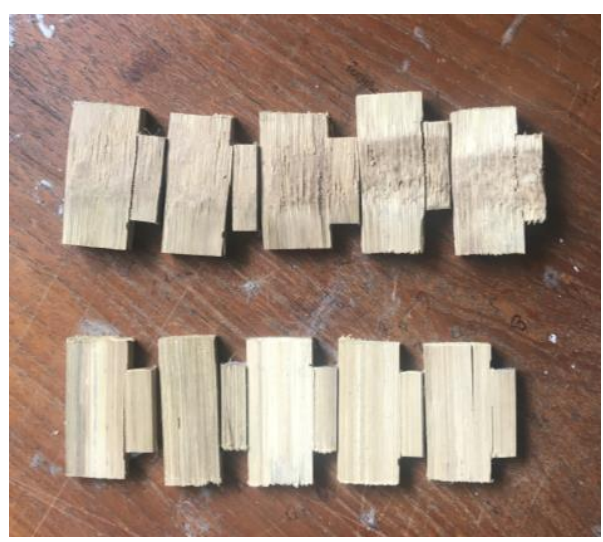

Fig. 15 - Failure pattern of shear test specimen

Vertical crack lines in dedicated area were the evidences that specimens experienced shear failure (Fig. 15). Shear strength of the center node and internode bamboo specimens are reported in (Fig. 16).

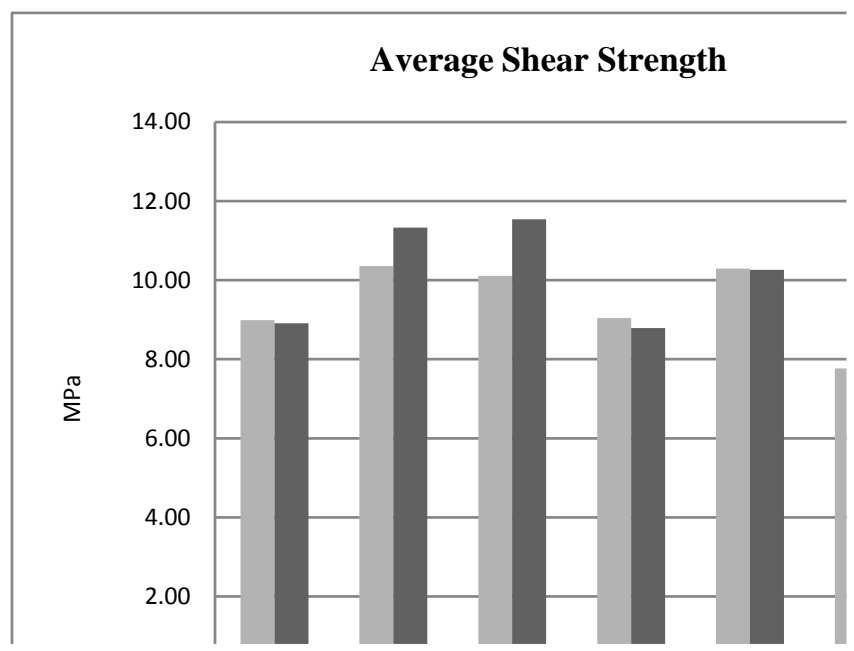

Fig. 16 - Shear strength test result 
The test results show that the shear strength at $0 \%, 10 \%, 20 \%, 30 \%$, and $40 \%$ of borax solution percentage display no differences. However at $50 \%$, and $60 \%$ of borax solution percentage, the shear strengths have decreased. Node provides small effects on shear strength to the bamboo specimens. Previous research by Oka et al., has reported that the average shear strength in node region accounted for $7.77 \mathrm{MPa}$, while average shear strength in internode region was 7.60 $\mathrm{MPa}$, which also indicate that node provides small effects on shear strength to the bamboo specimens (Oka et al., 2014).

\subsection{Bending Strength}

The bending test is conducted by not using full scale round of bamboos beam, but it only uses the bamboo strip specimen with center node and without node (internode). The following Fig. 17 shows that bending failure of internode specimen occurred at the center of the specimen, while in the center node specimen had slightly of the bending failure off the center of the specimen, or after the node region.

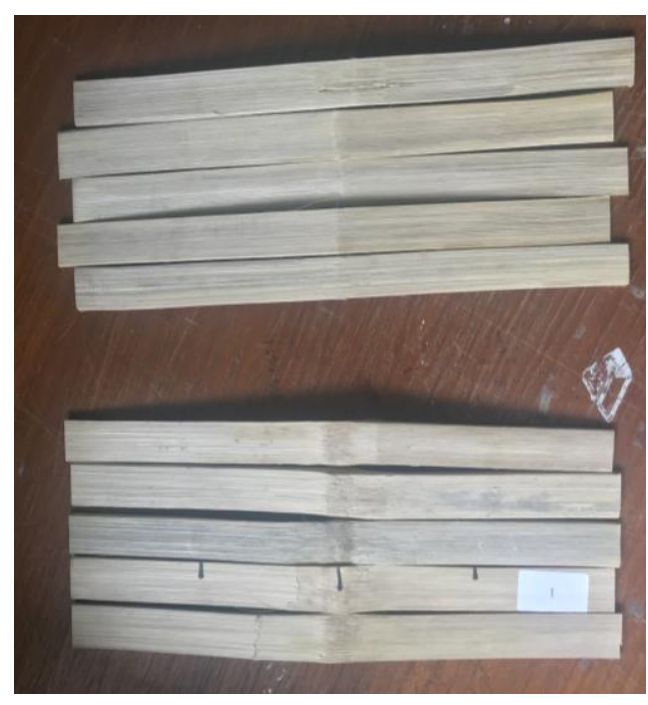

Fig. 17 - Failure pattern of bending test specimen

Bending strengths of the center node and internode bamboo specimen are reported in the following Fig. 18.

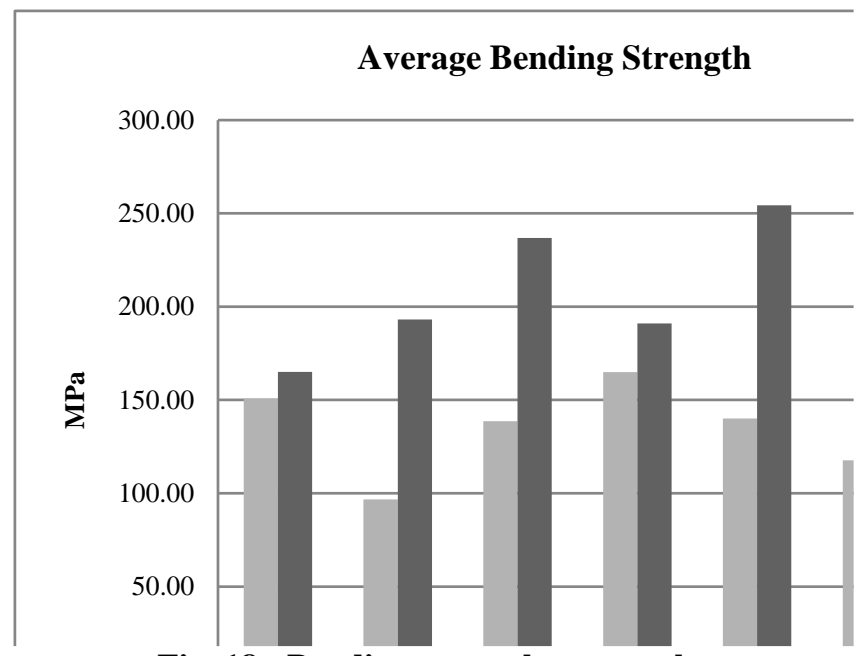

Fig. 18 - Bending strength test result

The strength test results showed that the addition borax solution mostly reduced the bending strengths of to the internode of bamboos specimens, only for the $30 \%$ of concentration provided a small effect to the strength, whereas the bending strengths of the nodes were increased mostly increased by the addition of this solution. The node parts of bamboos give additional strength to the bending properties. As it has been reported by Grnanaharan et al. that the strength of Guadua bamboos had different properties after being tested in different procedures due to the split/ strip specimens, indicating the importance of MOR and MOE to each split specimens (Gnanaharan, Janssen, \& Arce, 1995). 
The results show that the highest bending strength of the specimens was accounted for around $250 \mathrm{MPa}$ with additional of $40 \%$ of borax solutions.

\section{Conclusion}

This study indicates that Borax solution as preservative is not only useful for preventing insects and fungal attacks, but also has potential to increase mechanical properties of bamboo culm. Compression, tension, shear, and bending strength test that conducted in this study shows that borax solution can increase the compression, tension, and bending strength in significant number. This effect helps bamboo to be used as construction material. On the other hand, the experiments conducted also showed that nodes in bamboo culm had negative effect in tension strength, while the positive effects were presented in bending strength as well as in compressive and shear strength even though in small percentage. The bamboo strip specimens testing procedure for shear and bending strength also gives significantly different result compared to previous research that those used round specimens.

\section{Acknowledgement} Utara.

This research was supported by the program of Penelitian Dasar TALENTA funded by the Universitas Sumatera

\section{References}

22157-1, I. (2004). Bamboo —Determination of physical and mechanical properties - Part 1: Requirements.

22157-2, I. (2004). Bamboo - Determination of physical and mechanical properties - Part 2: Laboratory Manual.

Awalluddin, D., Mohd Ariffin, M. A., Osman, M. H., Hussin, M. W., A. Ismail, M., Lee, H.-S., \& Abdul Shukor Lim, N. H. (2017). Mechanical properties of different bamboo species. MATEC Web of Conferences, 138, 01024.

Bhawan, V., \& Marg, S. J. S. (2007). Preservation of Bamboo.

Gnanaharan, R., Janssen, J. J. A., \& Arce, O. (1995). Bending Strength of Guadua Bamboo. International Network for Bamboo and Rattan. New Delhi.

Larasati, D. (2007). Towards an integral approach of sustainable housing in Indonesia: with an analysis of current practices in Java. Design Academy, Eindhovan. Technische Universiteit Delft. Retrieved from http://www.narcis.info/publication/RecordID/oai:tudelft.nl:uuid:d9e07749-9bcb-4da6-beb2-e78823eaebae

Liese, W. (2007). Protection of bamboo structures. Annals of Warsaw University of Life Sciences, Forestry and Wood Technology.

Liese, Walter, \& Kumar, S. (2003). Bamboo Preservation Compendum. International Network Bamboo Rattan.

Ninez, K., Prinindya, N., \& Ardiansyah, L. (2014). The Effect of Chemical Substance and Immersion Time of Dendrocalamus asper as Chemical Preservation Treatment. International Journal of Advances in Materials Science and Engineering (IJAMSE), 3(1), 1-13.

Oka, G. M., Triwiyono, A., Awaludin, A., \& Siswosukarto, S. (2014). Effects of node, internode and height position on the mechanical properties of gigantochloa atroviolacea bamboo. Procedia Engineering, 95(Scescm), 31-37.

Saputri, A. (2012). BIODIVERSITAS BAMBU DI SUMATERA UTARA BAGIAN TIMUR. Universitas Sumatera Utara.

Schmidt O, Wei DS, Tang TKH, L. W. (2013). Bamboo and fungi. Journal of Bamboo and Rattan, 12(january), 0-14.

Suprapti, S. (2010). Decay resistance of five Indonesian bamboo species against fungi. Journal of Tropical Forest Science, 22(3), 287-294.

Tang, T. K. H., Schmidt, O., \& Liese, W. (2009). Environment-friendly short-term protection of bamboo against molding. Journal of the Timber Development Association of India, 55(August), 8-17. 